\title{
DIE SKRIFTUURLIKE BEGINSEL TEN GRONDSLAG VAN ART. 36 VAN ONS NEDL. GEL. BELYDENIS.
}

\section{Inleidend :}

Met hierdie opstel word daar geensins beoog om 'n hewige polemiek oor die saak aan te knoop nie, want ons besef dat die opinies onder Gereformeerdes op hierdie punt taamlik uiteenlopend is. Wat ons beoog, is net om tot dieper besinning te roep oor hierdie belangrike artikel in ons Nederlandse Geloofsbelydenis en om aan te toon dat die goeie reg van hierdie artikel in ons belydenisskrifte nie so maklik te betwis is as wat meesal gedink word nie.

Ter inleiding wil ons kortliks let op die stempel wat Art. 36 dra, en daarna 'n kort inhoudsanalise doen.

\section{(1) Die Stempel wat Art. 36 dra:}

Met die deurlees van dic artikel blyk dit dadelik dat ons dit hier nie te doen het met 'n liberalistiese of ,neutrale," of Rooms-Katolieke of Fascistiese of Nasionaal-Sosialistiese of Bolsjewistiese staatsopvatting nie, maar met 'n Calvinistiese of nader nog 'n „Calvynse" staatsopvatting.

Dat dit die geval is, blyk eerstens uit die feit dat Art. 36 byna letterlik uit Calvyn se Institusie saamgestel is. T.o.v. die positiewe taak van die owerheid sê Calvyn bv. „maar de burgerlijke regeering heeft tot taak om, zoolang wij onder menschen leven, den uiterlijken Godsdienst te ondersteunen en te beschermen, de gezonde leer der vroomheid en den staat der Kerk te verdedigen." 1) Voortgaande betoog Calvyn dat die owerheid noodsaaklik is om die boosheid van die mensheid te beteuel, en dan volg "opdat er geen afgodendienst, geen heiligschennis van Gods Naam, geen lasteringen tegen zijn waarheid en andere kwetsingen van de religie openlijk zouden opduiken en zich onder het volk verbreiden, opdat de openbare rust niet verstoord zou worden. Kortom, opdat onder de christenen een openbare gedaante van religie zou zijn en onder de menschen menschlievende omgang zou bestaan."

Tereg merk Dr. van Lonkhuyzen op dat die stempel van Art. $36 \mathrm{Cal}-$ vinisties is "Want zooals men weet, zijn de bekende woorden van Art. 36 Nederlandsche gelonfsbelydenis over de taak der Overheid inzake de religie, uit de Institutie van Calvijn overgenomen," en verder: „men ziet

(1) Calvyn Institusie IV, 20, 2.

(2) Institusie IV, 20, 3. 
hier: in de Institutie worden dezelfde gedachten, ja dezelfde woorden gegeven als in Art. 36." 1).

Die drievoudige taak van die owerheid, volgens Calvyn, nl. om geregtigheid onder die mense te beoefen, om die godsdiens te beskerm en om die publieke eerbaarheid te bewaar, word dan ook duidelik in Art. 36 weerspiëel.

Voorts blyk Art. 36 eg Calvinisties te wees in die onderskeiding wat dit maak tussen Staat en Kerk, en ook in die eis dat God op staatkundige gebied geëer en gedien moet word.

(2) Korte inhoudsanalise van Art. 36.

Hierdie artikel kan as volg onderverdeel word:

(a) Die Instelling van die Owerheid: dit geskied deur God, „Ons glo dat onse goeie God vorste en owerhede verorden het."

(b) Die Rede vir die instelling van die owerheid: „Vanweë die bedorwenheid van die menslike geslag."

(c) Die Doel van die owerheidsinstelling: „Omdat dit Sy wil is dat die wêreld geregeer moet word deur wette en regeringe, dat die losbandigheid van die mense bedwing kan word en alles met goeie orde onder die mense kan geskied."

(d) Die middel ter beskikking van die Owerheid: „Met dié doel het $\mathrm{Hy}$ die owerheid die swaard in die hand gegee om die kwaaddoeners te straf en die vromes te beskerm."

(e) Die Amp van die owerheid: „En hulle amp is om nie alleen ag te gee op en te waak oor die burgerlike regering nie, maar ook om die hand te hou aan die heilige Kerkdiens, om te weer en uit te roei alle afgodery en valse godsdiens, om die ryk van die Antichris te gronde te rig en die Koninkryk van Jesus Christus te bevorder, die Woord van die Evangelie orals te laat preek, sodat God deur elkeen geëer en gedien word, soos Hy in Sy Woord beveel."

(f) Die Plig van die onderdaan teenoor die owerheid: „Verder is elkeen, van watter hoedanigheid, toestand of staat hy ook mag wees, verplig om

(i) hom aan die owerhede te onderwerp;

(ii) belastings te betaal;

(iii) aan hulle eer en eerbied te betoon;

(1) Ger. Theol. Tijdschrift, Nov. 1938. Dr. J. van Lonkhuyzen: De blijvende Schriftuurlijke grondslag van Art. 36 onzer Nedl. Gel. 
(iv) en hulle gehoorsaam te wees in alles wat nie stry met die Woord van God nie."

(v) en vir hulle voorbidding te doen.

Die doel van dit alles is: „sodat die Here hulle mag bestuur in al hul weë en ons ' $n$ rustige en stil lewe kan ly in alle Godsvrug en waardigheid."

(g) Die verwerping van dwaalleringe: „Wat dit betref, verwerp ons die Wederdopers en ander oproerige mense; en in die algemeen almal wat die owerhede en regeerders verwerp en die regterlike mag omver wil stoot, wat die gemeenskap van goedere invoer en die eerbaarheid wat God onder die mense vasgestel het, in verwarring bring."

$\mathrm{Na}$ hierdie inleidende opmerkinge wil ons oorgaan eerstens om die positiewe implikasies van hierdie artikel t.o.v. die owerheid te trek, om dan tenslotte stil te staan by aanvegtinge van negatiewe aard.

I.-Positiewe Implikasies van Art. 36.

Die opvatting van Art. 36 is die Calvinistiese opvatting van 'n vrye staat, onafhanklik en onderskeie van die kerk. Dis 'n staat selfstandig in eie bevoegdheid. Reeds in sy Institusie het Calvyn 'n duidelike onderskeiding gemaak tussen tweeërlei regering in die wêreld $\mathrm{nl}$. die burgerlike en die kerklike regering. Hierdie regeringe mag nie vermeng of ineengesmelt word nie. 1) Tientalle jare het Calvyn gestry vir die vrymaking van die kerk van die staat en dus ook vir die staat se vrymaking van die bande van die kerk. 2)

Hierdie vrye Christelike owerheid moet dan die volgende kenmerke dra:

(1) As dienaresse van God moet die owerheid op sy terrein vir die eer van Gods naam waak.

(2) Die owerheid is in sy regspositivering gebonde aan Gods Woord.

(3) Die owerheid is geroepe om teen valse godsdienste en afgodery op te tree en om die Christendom te beskerm.

Laat ons op elkeen van hierdie punte afsonderlik ingaan.

(1) As dienaresse van God moet die owerheid op sy terrein vir die cer van Gods Naam waak.

In die algemene genade fungeer die owerheiu as instrument van God on die ongebondenheid van die sonde te stuit. As dienaresse van God moet dit die samelewing bewaar van totale verwoesting deur die sonde. 3 ) $\mathrm{Nie}$ tevergeefs het God die owerheid die swaard in die hand gegee nie!

(1) Bohatec: Calvins Lehre von Stant und Kirche S. 616.

(2) Vgl. Doumergue II, p. 84-129 en III, 23-307.

(3) A. Kuyper: Het Calvinisme, bl. 74. 
Oor die taak van die owerheid om God te verheerlik deur die gesag te handhaaf, geregtigheid onder die mense te beoefen, te sorg vir orde en eerbaarheid tot steun en veiligheid van die onderdane, bestaan daar geen verskil van opinie nie, maar wanneer daar, in ooreenstemming met Calvyn, geëis word dat die owerheid ook 'n positiewe taak teenoor die Christelike religie as sodanig het, dan loop die opinies uiteen. Calvyn het gesê dat die owerheid vir die eer van Gods Naam moet waak ook op openbare terrein. 1). In alles moet Gods eer gesoek word: dit is dic doel van skepping en herskepping. Dit is ook die doel van die owerheid. Alles uit God daarom alles vir God en alles onder God. Daar is geen dualistiese natuurgenade-leer hier nie, maar elke amp, elke arbeid is 'n roeping van God. En wel 'n roeping om God te dien ooreenkomstig die eise van Sy Woord. Dit geld ook van die owerheid: „Evenzeer als de predikers Christus dienen in hun ambt in de kerk-dienen de Overheden God in hun ambt in den Staat." Dit sou vreemd wees, meen Calvyn, as die owerheid oor alles moes waak, behalwe vir die eer van Hom wie se stadhouer hy is. En vir Sy eer allereers! En tereg merk Dr. van Lonkhuyzen hierby op: „Hier ligt een Schriftuurlijke redeneering welker logische kracht kwalijk kan ontkend worden." 2).

Dr. van Lonkhuyzen meen ook 'n definitiewe kentering te sien by Gereformeerde denkers in dié sin dat hulle Kuyper se ou standpunt dat die owerheid niks met die geopenbaarde waarheid sou te doen hê nie, m.a.w. dat die owerheid op geloofsgebied maar moet ,laat groei wat wil groei," 3) laat vaar het. Ja, hy toon aan dat Kuyper in sy latere werk "De Gemeene Gratie" al self tot 'n sekere mate die onhoudbaarheid van sy vroeëre standpunt ingesien het en die owerheid tog gaan bind het aan die geopenbaarde wil van God. 4) Volgens hierdie gekenterde rigting moet godslastering b.v. as sodanig deur die owerheid gestraf word en nie net omdat dit die publieke opinie skok nie. 5) Treffend sê Dr. van Lonkhuyzen ,het gaat daarover of in een Christelijke natie op publiek terrein (het terrein der Overheid) propaganda van het ongeloof voor de Overheid evenveel recht heeft als de prediking van het Evangelie? Het gaat daarover of godslastering in een christelijke natie op openbaar terrein evenveel recht heeft als verheerlijking van Gods Naam? Het gaat daarover of de godsdienstige dan wel de ongodsdienstige, ja atheïstiese

(1) Calvyn: Institutie IV, 20, 3.

(2) Gereformeerd Theologisch Tijdschrift, Nov. 1938, bl. 521.

(3) A. Kuyper: Ons Program, bl. 88, 89.

(4) Ger. Theol. Tijdsch., Nov. 38, bl. 480.

(5) A. Kuyper: Het Calvinisme, bl. 95. 
ontwikkeling van een volk een zaak is waar de Overheid, mitsdien met leede oogen, maar voorts met slappe handen bij moet staan? Het gaat daarover of in een Christennatie de Overheid moet toelaten dat Communistische of Atheïstiese propaganda in woord en geschrift zich vrij mag roeren?" En hier meen hy (en o.i. tereg) om teênoor Kuyper dit as die dure plig van die Christelike owerheid te stel om hierdie dinge teë te gaan, omdat die owerheid die dienaresse van God is en geroepe is om vir die eer van Sy Naam in die bresse te tree.

Vervolgens let ons op:

(2) Die owerheid is in sy regspositivering gebonde aan Gods Woord.

Die owerheid het sy regsgrond in God, die Absolute Wet, 1) en alleen onderworpenheid aan die wet van God kan die hoogste vryheid aan die christelike staat skenk. God het norme en wette vir Sy skepping vasgelê in die natuurwet, wat egter die lig van die Besondere Openbaring nodig het voordat dit suiwer gepositiveer kan word. En uit hierdie „positiewe reg," wanneer dit geskend word, vloei verskillende strawwe voort. Die strawwe kan egter verskil na gelang en aard van omstandighede. Die owerheid mag nie bandeloos wees in sy regspositivering nie maar is gebonde aan die natuur- en sedewet en is verantwoording verskuldig aan God. Vir Calvyn is die staatsreg sowel sedelik as juridies, en albei is veranker in God. 2) Die staat is dus gebonde an beide Tafels van die wet met die hoogste doel om God en die naaste te dien.

Interessant is dit om die politiese betekenis van die Tien Gebooie na te gaan soos Calvyn dit gesien het. Die owerheid moet God liefhê (Eerste Tafel) en dit sluit in dat die owerheid op sy terrein God sal erken en waak vir die eer van Sy Naam. Hiertoe behoort ook die beskerming van die christelike geloof en die Godsopenbaring (die Bybel). Dit alles word gedek deur die eerste gebod. Die tweede gebod eis die beskerming van die christelike eredienst. Voorts moet die owerheid die ontheiliging van Gods Naam straf (derde gebod) en ook van Gods Dag (vierde gebod).

Die Tweede Tafel eis dat die owerheid sy onderdane moet liefhê en hul moet beskerm deur regsordening en regspraak. Op hierdie gebied moet die owerheid optree teen diefstal, moord, laster, meineed ens. ens.

Vas staan dit vir my in elk geval, dat 'n christelike owerheid gebonde is aan die Heilige Skrif. Om die owerheid bloot te beperk tot die natuurwet of nader: tot die norme op die terrein van die algemene genade, soos Dr. Kuyper wou, is onmoontlik, want konsekwent deurgevoer, gee dit vir jou 'n naturalistiese i.p.v. 'n christelike staat. Nee die wette van die alge-

(1) L. J. du Plessis: Die stantsteorie van Jean Calvin . . . " BI. 26.

(2) Bohatec: Calvins Lehre von Staat und Kirche, S. 71. 
mene genade moet belig word deur die lig van Gods Woord, omdat die menslike verstand en hart deur die sonde so verduister en bedorwe is, dat hy ook die wette op die terrein van die algemene genade nie suiwer kan verstaan nie, laat staan nog suiwer positiveer!

Voorts wil ons meer breedvoerig stilstaan by 'n derde kenmerk van 'n christelike owerheid t.w.

(3) Die owerheid is geroepe om teen valse godsdienste en afgodery op te tree en om die christendom te beskerm.

Dikwels word aangevoer dat hierdie stelling, in Art. 36 vervat, nie alleen ongeoorloofd is nie, maar beslis ook onchristelik. Ons wil die negatiewe vraag of hierdie stelling nie die deur oopmaak vir geloofsinkwisisie en die miskenning van die pluriformiteit van die kerke, nie hier behandel nie maar laat oorstaan vir 'n volgende artikel wat sal poog om te antwoord op besware teen Art. 36. Hier wil ons net positief uiteensit wat die Hervormers daaronder verstaan het.

Calvyn het dit as die plig van die staat beskou om aartsvyande van die godsdiens uit te roei, nie terwille van die kerk alleen nie, maar veral terwille van die staat self. Want sulke mense wat die grondslae van die religie aanval en ondermyn, doen dieselfde met die grondslae van die sedelikheid en van die staat. Tussen die christelike godsdiens en die sedewet is daar die allernouste verband, ja laasgenoemde is gewortel en gegrond in eersgenoemde. As die staat dus moet sorg dat die sedewet gerespekteer en gehou word, moet hy dieselfde doen t.o.v. die christelike godsdiens. 1)

Hoewel dit nou by uitnemendheid die taak van die kerk is om deur die verkondiging van die Woord die Koninkryk van God uit te brei, moet die kerk nie wyser as God wees om die staat, wat deur God ingestel is ter bevegting van die sonde, die reg te betwis om in sekere omstandighede dic kerk te help teen uitbarstinge van die ongeloof nie. Sulke gevalle kom voor wanneer aartsvyande van die godsdiens die grondslae van kerk en samelewing, die "humanitas" ondermyn, 2) wanneer die openbare gedaante van die religie en mensliewende omgang vernietig sou word. 3)

Daar is dus onderskeid tussen ketters en ketters. Jode, Turke, ja selfs Rooms-Katolieke, moet nie deur die staat vervolg word nie, 4) ook nie persone wat op dogmatiese leerpunte afwyk nie 5) maar wel persone

(1) Bohatec: Calvins Lehre von Staat und Kirche, S. 621.

(2) J. Koopmans: Nederlandsche Geloofsbelydenis, bl. 225.

(3) Calvyn: Institutie IV, 20, 3.

(4) Bohatec: Calvins Lehre von Staat und Kirche, S. 624.

(5) Ibidem, S. 623. 
wat beoog ,'n verskeuring en uitdelging" van die religie as sodanig. Hieronder klassifiseer Calvyn veral persone wat die christelike waarheid eenmaal onderskryf het maar later in goddelose afval hul haat teen die godsdiens gerig het. Van 'n sekere geval sê hy „Hy het geen proklamasie uitgevaardig dat buitestanders gestraf moet word nie, maar diegene wat, nadat hulle kennis van die wet bely het, op verraderlike wyse daarvan afgedwaal het. Op hierdie wyse is weggeneem die beswaar wat oningeligtes mislei het, aangesien hul gevrees het dat onder hierdie voorwendsel pouslike beule beskerm sou word tot wreedhede. Daarom het ons nie magistraatsampte ingestel met 'n roekelose en blinde mag nie, en nadat die gewenste beskerming (versekering) van hulle verkry is, kan elke godsdiens voortgaan op eie manier (ek kursiveer)." Voortgaande wys die Hervormer beslis die gedagte van geloofsinkwisisie af en sê dan „Hiertoe is die beswaar opgelos wat vra of Jode, Turke en dergelike klasse teruggebring moet word tot die geloof in Christus deur die swaard. Want God het bepaald nie beveel dat die swaard moet getrek word teen almal sonder onderskeid nie, maar die afvalliges, wat hulself goddelooslik vervreem van die ware godsdiens en ander tot dergelike dwaling oorhaal, onderwerp Hy aan 'n regverdige straf." 1)

Verdere lig op hierdie vraagstuk word gewerp deur die interessante en deeglike studie van Prof. L. J. du Plessis „Die Staatsteorie van Jean Calvin in verband met die wetenskap en staatspraktyk van sy tyd." Prof. $\mathrm{du}$ Plessis kom tot die gevolgtrekking dat volgens Calvyn daar alleen oorgegaan moet word tot die straf van valse leraars ,in dié gevalle waar die suiwere leer ontwyfelbaar gesaghebbend as openbare godsdiens in die bepaalde staat vasgestel is en waar die valse leer gerig is op die omverwerping daarvan, m.a.w. wanneer die valse leer 'n vergryp sou wees teen die regsorde self in sy fondamente. Nie kettery moet dus gestraf word nie, maar rewolusionêre skending van die reg t.o.v. die religie." 2)

Is hierdie plig, aan die owerheid toegeskryf, nou billik en regverdigbaar? O.i. ja, want daar is 'n onlosmaaklike verband tussen valse godsdiens, afgodery en ongeloot aan die een kant en onsedelikheid en rewolusie aan die ander kant. Reeds Groen van Prinsterer het dit onweerlegbaar aangetoon in sy skitterende en beroemde werk „Ongeloof en Revolutie." Ateïsme en afgodery voer tot rewolusic, betoog hy. 3) Netsomin as wat

(1) Calvyn: Opera 8, 475. Uit die Latyn vertaal by Bohatec S. 622 . voetnoot.

(2) L. J. du Plessis „Dle staatsteorie van Jean Calvin . . . bl. 58.

(3) Ongeloof en Revolutie, vgl. o.a. blss. 122, 174, 218, 302, 203, 159 e.v., 169, 174, 123. 
God neutraal staan teenoor die Satan en die sonde van ongeloof en afgodery, netsomin mag, of kan, 'n christelike staat daarteenoor neutraal staan. Hier bestaan ' $n$ antitese te diep om oorbrug te word deur 'n blote neutraliteitspostulaat. Immers dit is onmoontlik om neutraal te staan t.o.v. van God, Sy Kerk, en die Christendom. Van die indiwidu en volk eis God dat hulle nie sal "hink op twee gedagtes nie." Vanwaar dan die ongerymdheid dat die owerheid, wat uit ' $n$ indiwidu of indiwidue bestaan, dit moet doen? Is Christus dan nie ook die Koning van die konings en die Heer van die here nie? Of moet die christen dan, as hy aan die hoof van die regering kom, sy Christus verloën en „neutraal” gaan staan teenoor alles wat Sy Koninkryk raak? Sovele punte van kontak is daar tussen staat en kerk, en moet die christelike owerheid nou terwille van die ongeloof „neutraal" optree?

Nee die sogenaamde "neutraliteitsapostels" is niks anders as verlynde ongeloofsapostels nie. Kragtig getuig Groen: „wie de godsdienst niet bemint, haat ze. De haat tegen het Evangelie is het kenmerk van revolutie, haar antichristelijk karakter." Dit is dié rigting ,die het christendom als eene bijgelovige dwaasheid veracht, voor wie het cen voorwerp . . . . van haat is, ja van volkomen dweepzieken haat, als zijnde deze tot dusver onuitroeibare sekte het meest krachtige en dus ook het meest heilloze beletsel van de ontwikkeling der menschheid. De zogenaamde „onzijdigheid" lost zich op in de meest verderflijke „eenzijdigheid" ten behoeve van het ongeloof, en loopt op een proselytisme der godsdienst van rede en natuur uit." 1).

Die owerheid is dienaresse van God en kan, ja mag nie neutraal staan teenoor die christendom nie. En dit terwille van homself! Die toelating van afgodery en valse godsdiens wreek homself in die openbare sedelike peil van 'n volk soos ons bv. die duidelike voorbeeld in die vooroorlogse Bolsjewistiese Rusland kon sien. En die openbare sedes is tog onbetwisbaar die terrein van die owerheid!

Nee, Calvyn en Guido de Bres was nie manne wat halwerweë teruggedeins het vir die konsekwensies van die christendom nie. Ook nie vir die konsekwensies daarvan op staatkundig gebied nie. Oral moet God geëer en gedien word, en dit kan bepaald nie geskied deur 'n owerheid wat agter die skuilmantel van "neutraal” gaan wegkruip sodra hy vit Christus en teen die ongeloof moet kies nie.

Die pluriformiteit van die kerke waarsku ons om nie een kerk as die enige en ware te beskou, waarbuite daar geen saligheid is nie, maar dit

(1) Groen van Prinsterer: Ongeloof en Revolutie, bl. 173-174. 
verbied ons seer stellig nie om te sê dat daar valse godsdienste en afgodery is nie. Eweso met die owerheid. Dit mag vir hom 'n moeilike kwessie wees om sy verhouding te bepaal teenoor die christelike kerke in sy grondgebied, maar m.i. is daar geen moeilikheid vir 'n christelike owerheid om by die lig van Gods Woord uit te maak wat vals en antichristelik is nie! Dis miskien 'n probleem vir die owerheid on te besluit watter van die christelike sektes geduld moet word, maar dis geen probleem om te sien dat die openbare ateïsme met sy militante houding teenoor die christendom terwille van die staat self uitgeroei moet word nie!

Hiermee het ons aan die einde gekom van ons positiewe uiteensetting van Art. 36. D.V. hoop ons om in 'n slotartikel die besware teen Art. 36 goed onder die oog te sien. Ongelukkig sal dit alles baie kursories moet geskied weens gebrek aan plaasruimte. Mag dan ook hierdie bydrae tot „Koers" strek tot die meerdere verheerliking van die Naam van onse God -soli Deo Gloria.

\section{F. N. VAN NIEKERK.}

Pos Pokwani,

Vaalhartz. 